\title{
Electric ANd Thermal ENERgy Production AND STORAge SYSTEM BY PINECONE WASTE
}

\author{
Nuno Domingues \\ Department of Mechanical Engineering, ISEL, Lisbon, Portugal
}

\begin{abstract}
Rural ecosystems are the main source of biomass used in the production of renewable energy in Portugal. However, it is based on pruning residues are most of the raw material for biomass leaving other opportunities aside. This paper highlights the role of pinecone waste without pinion for the energy sector. The present paper studies different solutions to enhance the use of the pinecones for energy proposes. The present paper also presents the different principal technologies.

It is possible to conclude that the use of residual biomass is a way to reduce the national dependence on energy imports (fossil specialties), decreases transport losses (by allowing local production and consumption locally) and encourages the management of forest areas (fixing people in rural areas and lowers the risk of fire).
\end{abstract}

\section{KEYWORDS}

Pinecones waste, energy production, energy storage, pellets.

\section{INTRODUCTION}

Currently in Portugal, the domestic production of primary energy in Portugal is based almost entirely on Renewable Energy Sources (RES). Renewable energy sources come from natural resources (water, wind, biomass, sun, and heat from the Earth) that renew themselves naturally and regularly, in a sustainable way, even after being used to generate energy (electricity or heat). These natural resources make it possible to produce hydro, wind, biomass, solar, ocean and geothermal energy. The European Union (EU) defined, through Directive 2009/28/EC, reformulated by EU Directive 2018/2001, on the promotion of the use of energy from renewable sources (RES), the objective of achieving, in Portugal and by 2020, a share of $31,0 \%$ of energy from renewable sources in gross final energy consumption and a share of $10.0 \%$ in the transport sector. In Portugal, Decree-Law No. 141/2010, amended by Decree-Law No. 39/2013, partially transposed the RES Directive, establishing national targets for the use of energy from renewable sources in gross final consumption energy consumption and energy consumption in transport in 2020, corresponding to $31 \%$ and $10 \%$, respectively, which were also assumed in the National Action Plan for Renewable Energies for the period 2013-2020 (PNAER 2020). Indicative interim targets (indicative path) were also set for the use of renewable energy in the gross final consumption of energy: $22.6 \%$ for the years $2011-2012$; $23,7 \%$ for $2013-2014 ; 25,2 \%$ in 2015 2016; and 27,3\% for 2017-2018. The PNAER also foresees, as an indicative target, an incorporation of $59.6 \%$ of renewable energy in electricity by 2020. In 2016, the European Commission presented the Legislative Package "Clean Energy for all Europeans" with the objective of promoting the energy transition in the 2021-2030 decade, and approved, in the EU Regulation 2018/1999, targets that aim to reach, in 2030, 32\% share of energy from renewable sources in gross final consumption, 32,5\% reduction in energy consumption, $40 \%$ reduction in 
greenhouse gases compared to 1990 levels, and 15\% reduction in interconnections electrical. As a result, Portugal drew up the National Integrated Energy and Climate Plan for the 2030 horizon (PNEC 2030), the main national instrument of energy and climate policy for the 2021-2030 decade. The PNEC 2030 is the following national criterion for 2030: reduce between $45 \%$ and $55 \%$ as an exemption from greenhouse gases, by reference to those registered in the year 2005; incorporate $47 \%$ of energy from renewable sources in the gross final energy consumption; achieve a $35 \%$ reduction in primary energy consumption with a view to better energy efficiency; reach $15 \%$ of electricity interconnections.

In the context of the Covid-19 pandemic, and the restrictions imposed by it, the year 2020 was atypical in terms of energy consumption (primary and final), with a reduced reduction, in particular for final energy consumption, due to reduction in the reduction of travel / mobility, with the transport sector being the one with the greatest impact on the reduction of final energy consumption (road and air transport). In 2019, the production of renewable energy was 6487 ktoe, of which about 46,6\% came from biomass. Heat pumps contributed 10,5\% and biofuels $5,4 \%$.

Figure 1 [1] shows the Annual RE Production mix in Portugal per year where it is possible to observe the evolution of the minimum trajectory of RES in the final gross energy consumption.

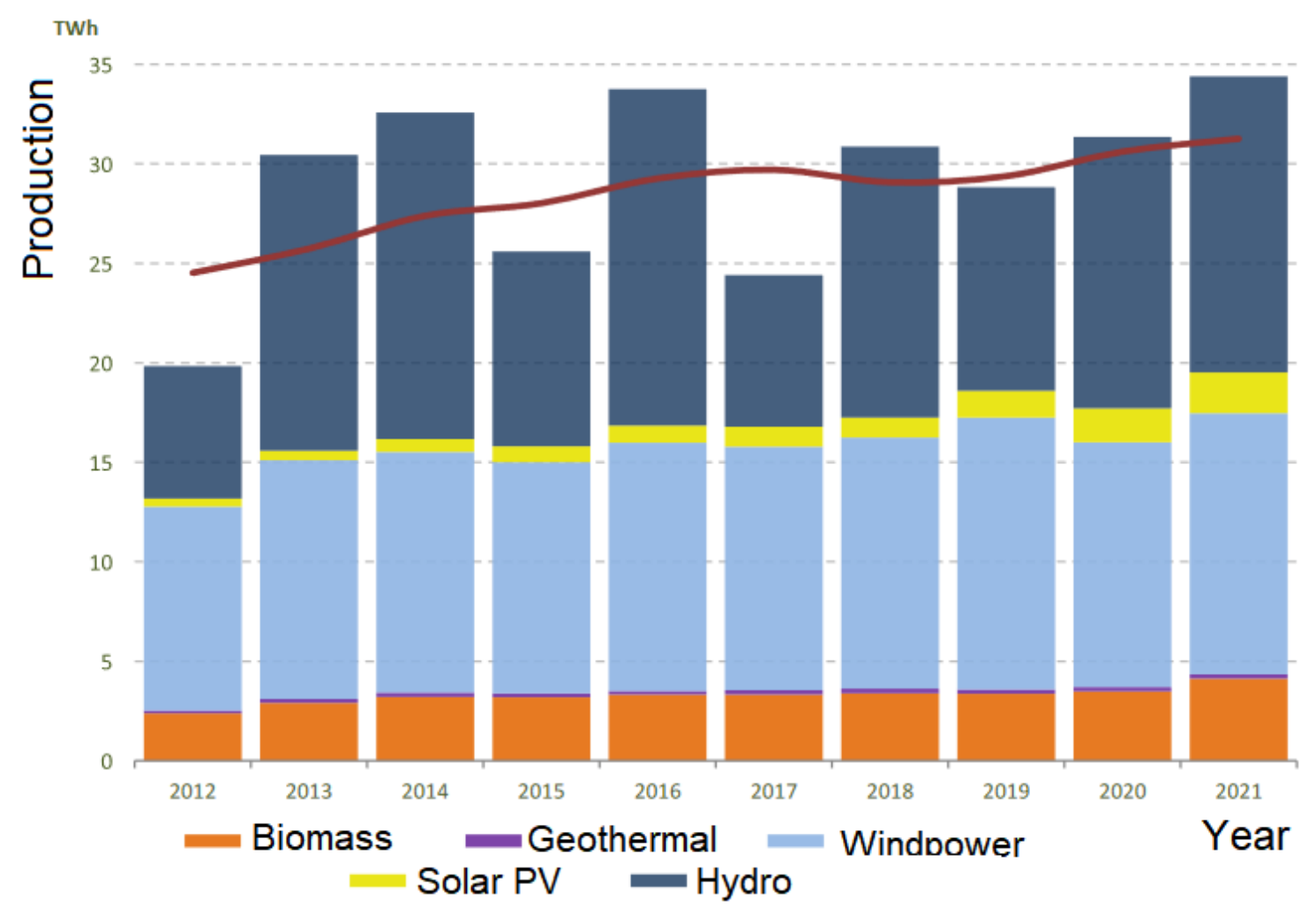

Figure 1. Annual RE Production mix in Portugal per year

The strategic importance of biomass in Renewable Energy Sources (RES) - which include, in addition to biomass, hydroelectric, wind, solar, geothermal and biofuels - has been constant over the past few years. Since 2010, biomass has ensured more than half of the production of renewable energy in Portugal and, in this period, the peak was reached in 2012, when biomass contributed to $60.1 \%$ of the total. After a drop to $50.8 \%$ in 2013, the trend returned to an upward 
trend between 2015 and 2017. In 2016 and 2017, approximately 57\% of biomass was used for transformation in thermoelectric plants with or without cogeneration, $34 \%$ was used directly for heat production, mostly in the residential sector, and the remaining $9 \%$ was exported in the form of pellets and briquettes. Most of the energy from biomass comes from forestry raw materials: vegetable and forestry residues, sulphitive liquors generated in the production process of the pulp and paper industry, pellets and briquettes. This contribution is essential to support the goals of the Community directive 2009/28/EC, which set Portugal's goal of incorporating $31 \%$ of Renewable Energy Sources (RES) in the gross final consumption of energy, by 2020. In 2017, the weight of RES was $28,1 \%$, slightly lower than the previous year, but more than 3,5 percentage points higher than the values of the beginning of the decade. There is an $8 \%$ increase in RES-sourced production in the moving year of September 2021, compared to 2020, with water rising by $9 \%$. The sharp drop in RES production in 2012 and 2017 was due to the droughts that occurred in those years.

Figure 2 [1] shows the RES production in Portugal by geographic area per year. It is possible to observe that the major sources are in the north-centre rural areas of the inland.



Figure 2. RES production in Portugal by geographic area per year

From 2012 to September 2021, the technology with the greatest growth in installed power was hydro $(1,6 \mathrm{GW})$. However, in relative terms, the technology that grew the most was photovoltaics, having evolved from an installed capacity of 244 MW to 1239 MW.

In Figure 3 [1] it is possible to observe the RES production mix in Portugal by County in 2019 and that the major sources are in the north-centre rural areas of the inland. 
Advanced Energy: An International Journal (AEIJ), Vol. 9, No. 1, January 2022

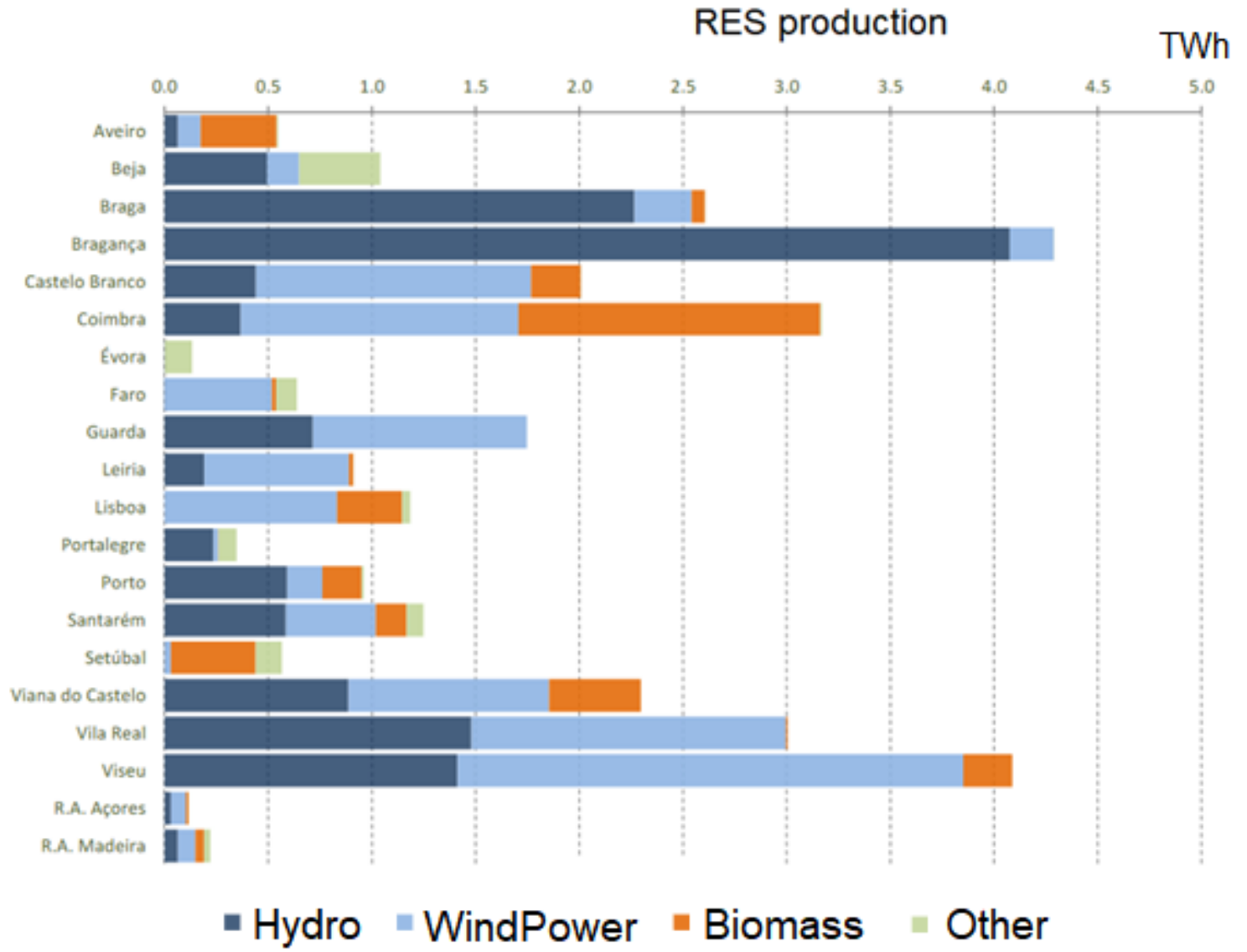

Figure 3. RES production mix in Portugal by County in 2019

Figure 4 [1] shows the RES production mix in Portugal from October of 2020 until September of 2021. It is possible to observer a slight increase of biomass but still a low share in the RES.

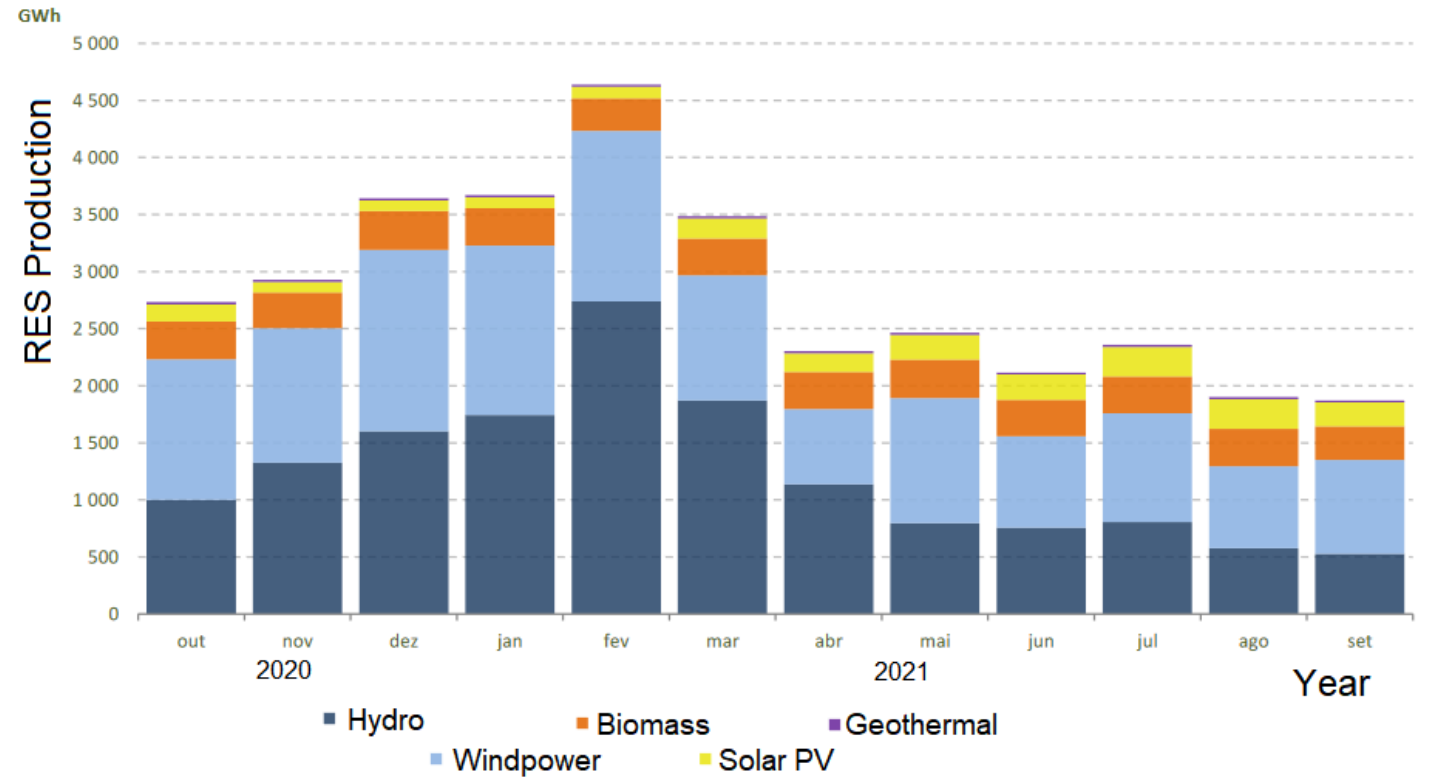

Figure 4. RES production mix in Portugal in 2020/2021 
The use of residual forest biomass for energy production is recognized as a sustainable resource in the context of energy transition and climate goals. Composed of leftovers from forestry activities, such as those resulting from thinning or exploration in the field (for example, bark, branches and stumps), the residual forest biomass can include other components, such as organic matter from invasive species (result of actions control of trees and shrubs that are harmful to ecosystems), trees attacked by pests and diseases that cannot be used otherwise and materials that result from the opening of fire barriers (firebreaks, for example). The use of firewood as a heating source is an ancient practice, but the versatility of biomass allows uses that go far beyond its domestic use in fireplaces or stoves, having become a significant source of renewable energy in Portugal.

To these residual and sustainable materials from the forest - called secondary forest biomass are added at least two more:

- Waste generated by forestry-based industries: cork dust, eucalyptus shavings and bark discarded in the production of paper pulp and even various by-products of these industries, such as the liquid resulting from cooking wood (usually called liquor), are examples of this.

- Forest-derived products, once consumed, can also contribute to energy production, valuing them in what will be the last stage of their life cycle.

Additionally, other organic waste can be considered as sustainable raw material for energy production, namely those come from agricultural and silviculture activities. That is the case of empty pinecones. After removing the pinions from the pinecones, it remains a waste that is mainly burned, normally in open fireplaces.

Figure 5 [2] shows the final energy consumption of bioheat in the different sectors in EU28 in 2018 in ktoe units and in percentage.

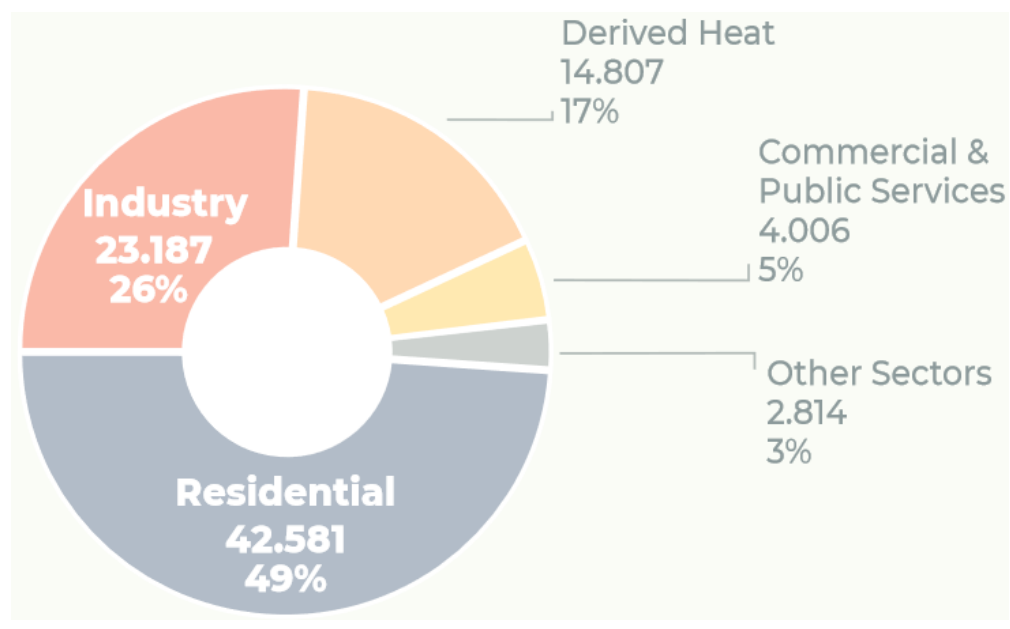

Figure 5. Final energy consumption of bioheat in the different sectors in EU28 in 2018

In $2018,49 \%$ of the bioheat in the EU was used by the residential sector, followed by industry (26\%) and district heating (17\%). In the residential sector small and medium size appliances are predominant, their modernisation (when necessary) and correct maintenance and installation are key to the abatement of air emissions. With $49 \%$ of bioheat consumed in the residential sector, it is small and medium appliances that dominate, with their modernisation, correct maintenance and installation becoming key to curbing air emissions. District heating networks are of equal 
importance to smart sector integration, as they not only increase energy efficiency but allow access for low carbon sources. Remarkably, 99\% of renewable heat in industry comes from biomass, demonstrating that bioenergy is fundamental in aiding industry's transition to carbon neutral energy systems.

Figure 6 [2] shows the share of biomass usage in the different industries in 2018 in EU28 Countries. In 2018, industry represented $16 \%$ of the final energy consumption of heat in the EU, with only $13 \%$ of this from renewables, and almost entirely bioenergy (99\%).

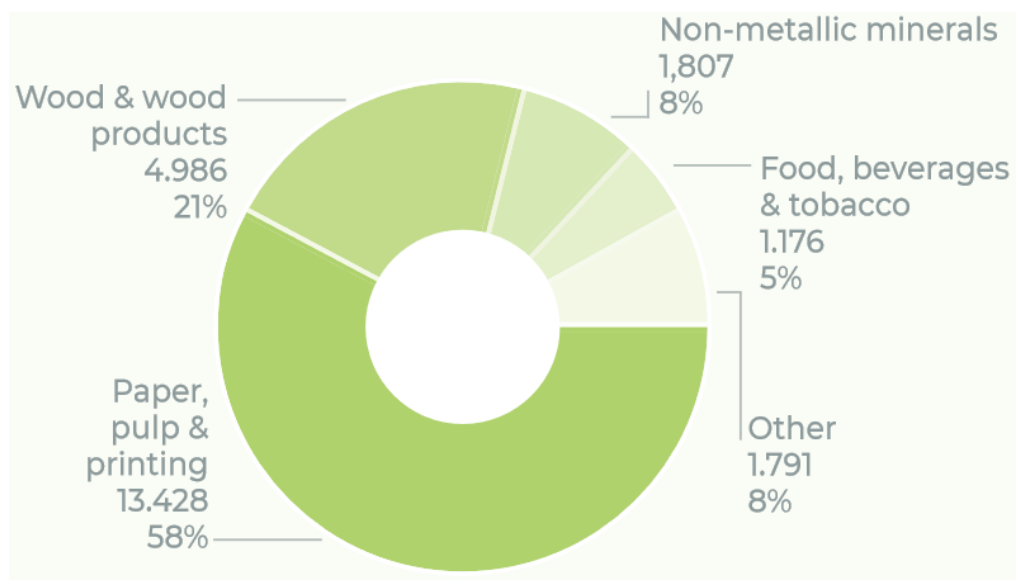

Figure 6. Share of biomass usage in the different industries in 2018 - EU28

District heating networks are essential to smart sector integration - they increase energy efficiency and enable to increase the share of renewables at local level. Yet, in the EU they remain largely reliant on fossil fuels, with renewables already greening $27 \%$ of their heat production. Nevertheless, this once again presents the potential for the decarbonisation of the industry and derived heat sectors, through the provision of an adequate policy framework and incentive schemes. District heating and individual biomass heating systems are an important part of the solution. Alongside energy efficiency, they offer an affordable and renewable source of heat. Now, more than ever, long-term strategies to decarbonise the building sector are needed to advance the switch from fossil to renewable solutions.

\section{Case Study for Portugal}

Combustion is the chemical reaction in which new substances are produced together with light and heat (burning of wood) or just heat (burning of methanol, a type of alcohol used as fuel).

Because it is a chemical process (the materials used before will be transformed into new materials), we can represent combustion through an equation, but it is necessary to inform that for a combustion reaction to occur it is necessary the presence of oxygen gas $(\mathrm{O} 2)$. Note below the equation that represents a combustion:

$$
\text { Fuel }+\mathrm{O}_{2} \rightarrow \mathrm{CO}_{2}+\mathrm{H}_{2} \mathrm{O}
$$

For the combustion reaction to happen, four key elements must be present, they are:

Fuel: material that will undergo transformation and feeds combustion. Example: gasoline.

Burmese: substance that gives life and sustains combustion. Example: oxygen gas.

Activation energy: it is an energy that will cause the combustion reaction. 
Advanced Energy: An International Journal (AEIJ), Vol. 9, No. 1, January 2022

Chain reaction: we can say that it is the combination of the three elements above, since one is related to the other, forming a cycle. Example of activation energy: a spark.

The materials that can be burned are varied, but not all material can be used as fuel. The greatest examples of fuels are organic compounds (substances that have hydrogen and carbon elements in their constitution), such as:

gasoline $(\mathrm{C} 8 \mathrm{H} 18)$
ethanol $(\mathrm{C} 2 \mathrm{H} 6 \mathrm{O})$
methanol $(\mathrm{CH} 4 \mathrm{O})$
glucose $(\mathrm{C} 6 \mathrm{H} 12 \mathrm{O})$

But it is interesting to note that some metals also suffer combustion, such as:

iron $(\mathrm{Fe})$

sodium $(\mathrm{Na})$

magnesium $(\mathrm{Mg})$

Because the reaction happens it is necessary that the fuels have chemical affinity with the burster, otherwise the process will not happen. There are some types of combustion, the most common being the following:

Complete combustion: this is the one in which water $(\mathrm{H} 2 \mathrm{O})$ and carbon dioxide $(\mathrm{CO} 2)$ are produced. Your flame is blue. Example: light a lighter or flame from the new stove.

$$
\mathrm{CH}_{4} \mathrm{O}+3 / 2 \mathrm{The}_{2} \rightarrow \mathrm{CO}+2 \mathrm{H}_{2}
$$

Example of a complete methanol combustion equation $\left(\mathrm{CH}_{4} \mathrm{O}\right)$

Incomplete combustion: it is the one in which water and carbon monoxide $(\mathrm{CO})$ are produced, with a smaller amount of carbon dioxide being produced as well. In addition to these products, this combustion produces soot (coal or carbon). Your flame is yellowish. Example: burn wood.

$$
\mathrm{CH}_{4} \mathrm{O}+3 / 2 \mathrm{The}_{2} \rightarrow \mathrm{CO}+2 \mathrm{H}_{2}
$$

Example of an incomplete combustion equation

Slow combustion: it is the one in which no light and heat are produced, besides happening very slowly, it is the combustion model that occurs with iron. It undergoes combustion, but does not produce carbon dioxide and water, produces rust. Example: Rust formation $(\mathrm{Fe} 2 \mathrm{O} 3)$ of steel straw (used for dishwashing).

$$
2 \mathrm{FE}+3 \mathrm{The}_{2} \rightarrow 2 \mathrm{Fe}_{2} \mathrm{O}_{3}
$$

The Lower Calorific Value (PCI) of the pinecone scale is $4 \mathrm{kWh} / \mathrm{kg}$ and humidity is quite variable:

. dry products $(<25 \%)$,

. wet products $(25-40 \%)$

. very wet products $(>40 \%)$.

Storage in a shed (16/18 months) lead to a moisture content between 15 to $20 \%$ of humidity. 
Advanced Energy: An International Journal (AEIJ), Vol. 9, No. 1, January 2022

The drier the fuel, the greater its calorific value. The greater the density of the dry product, the higher the thermal potential contained in a cubic meter, the less frequent the loadings and the greater the autonomy of the installation.

Table 1 shows the comparation between the different equipment's used to burn forest and silviculture residues.

Table 1. Equipment's used to burn forest and silviculture residues

\begin{tabular}{||l|l|l|l||}
\hline Equipment & Yield & Cost (Euro) & Other observations \\
\hline Fireplace & Low $(10 \%$ to $15 \%)$ & 250 to 1500 & Decorative element \\
\hline $\begin{array}{l}\text { Heat } \\
\text { recovery }\end{array}$ & Up to $60 \%$ & 300 to 2000 & $\begin{array}{l}\text { Adaptable to most fireplaces (works with air } \\
\text { or water) }\end{array}$ \\
\hline Salamander & Up to $75 \%$ & 300 to 2500 & $\begin{array}{l}\text { There are automatic feeding (works with air } \\
\text { or water) }\end{array}$ \\
\hline $\begin{array}{l}\text { Kitchen } \\
\text { stove }\end{array}$ & $60 \%$ to $65 \%$ & 400 to 2500 & $\begin{array}{l}\text { Can provide hot water to be distributed } \\
\text { throughout the house (radiators) }\end{array}$ \\
\hline Boiler & $60 \%$ to $75 \%$ & 300 to 3500 & $\begin{array}{l}\text { Requires a hydraulic system for heat } \\
\text { distribution }\end{array}$ \\
\hline
\end{tabular}

However, this waste can be used to produce energy (electricity or thermal) in a more efficient way. Also, there is an advantage of storage that brings flexibility to the electric energy system that is one of the problems that is align with the increase of the E-RES.

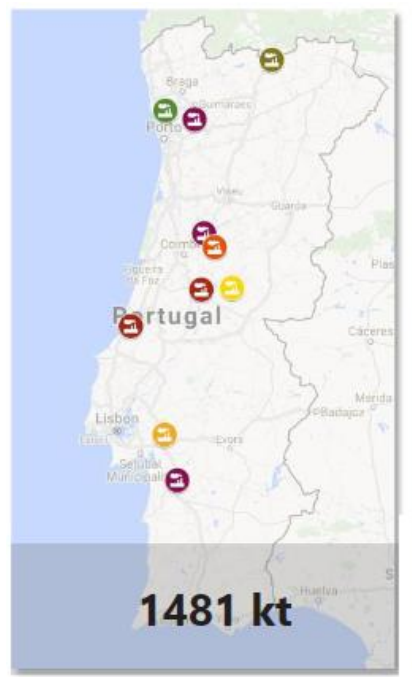

Pellet based

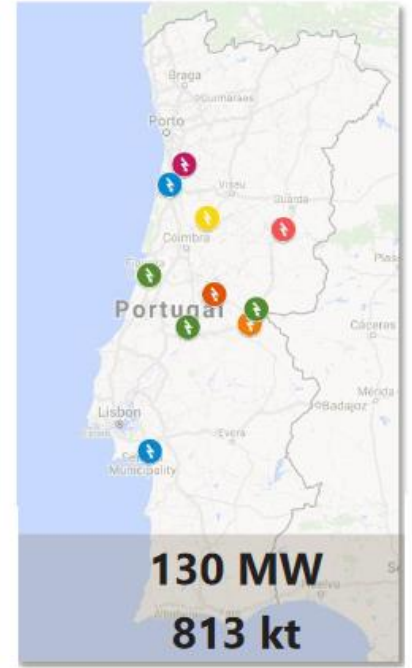

Thermal on service

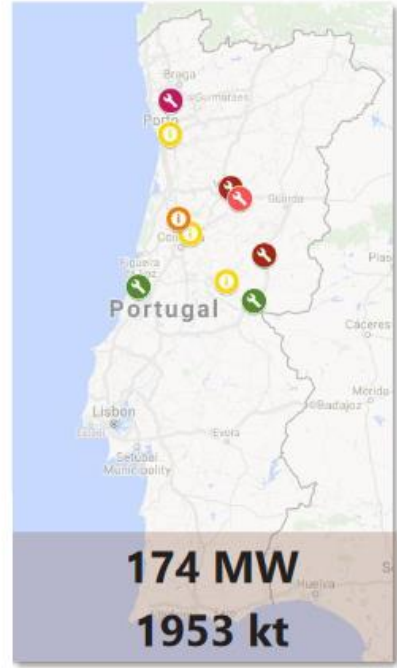

Thermal planned

Figure 7. Biomass demand distribution

Source: The Navigator, The importance of biomass, https://www.apren.pt/contents/documents/frederico-pisco.pdf

The use of thermal energy in cogeneration systems can be done in different ways: steam, thermal oil, hot water, hot air, etc. It can also be carried out in the form of cold, usually by producing cold or ice water $\left(5^{\circ} \mathrm{C}\right.$ to $\left.7^{\circ} \mathrm{C}\right)$ through absorption chillers). The use of thermal energy resulting from the cogeneration process for the production of refrigeration is called Trigeneration. The activity sectors with adequate conditions for the installation of cogeneration units correspond to industries or services that consume large amounts of thermal energy: refining, petrochemicals and 
chemicals, pulp and paper, ceramics, textiles and food. These industries are often planted in rural areas thereby, further advantages are applied. In the tertiary sector, cogeneration is usually associated with air conditioning in large-scale buildings or undertakings with central air conditioning: shopping centres, hospitals, hotels, swimming pools and leisure centres, hyper and supermarkets, office buildings and urbanizations with central air conditioning. In environmental terms, the use of useful heat recovered during a cogeneration process prevents the additional consumption of a fuel to produce the same thermal energy, thus reducing the emissions of greenhouse gases associated with the production of the two forms of useful energy in cause electricity and heat. Thus, cogeneration assumes a very important role in meeting the targets for reducing $\mathrm{CO} 2$ emissions into the atmosphere, assumed in international agreements.

Figure 8 [3] shows the percentage of incorporation of renewables in energy consumption, by sector in Portugal in 2019.

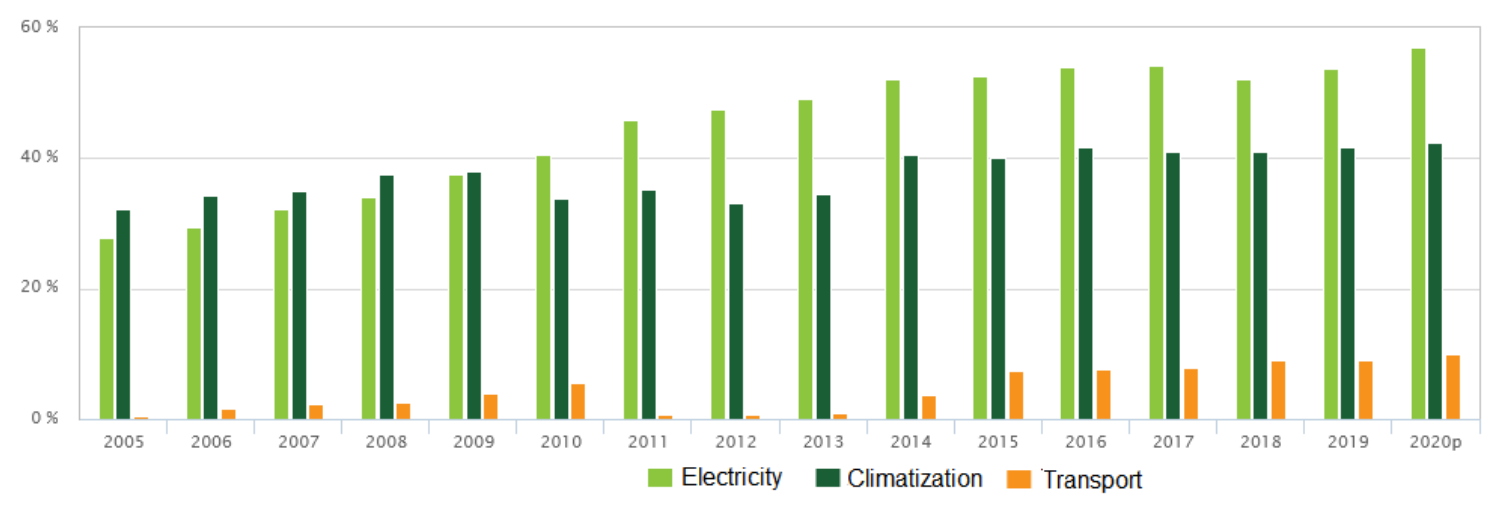

Figure 9. Percentage of incorporation of renewables in energy consumption, by sector, in 2019

Figure 9 [4] shows the percentage of incorporation of renewables in the electricity sector, in the EU-28, in 2019.

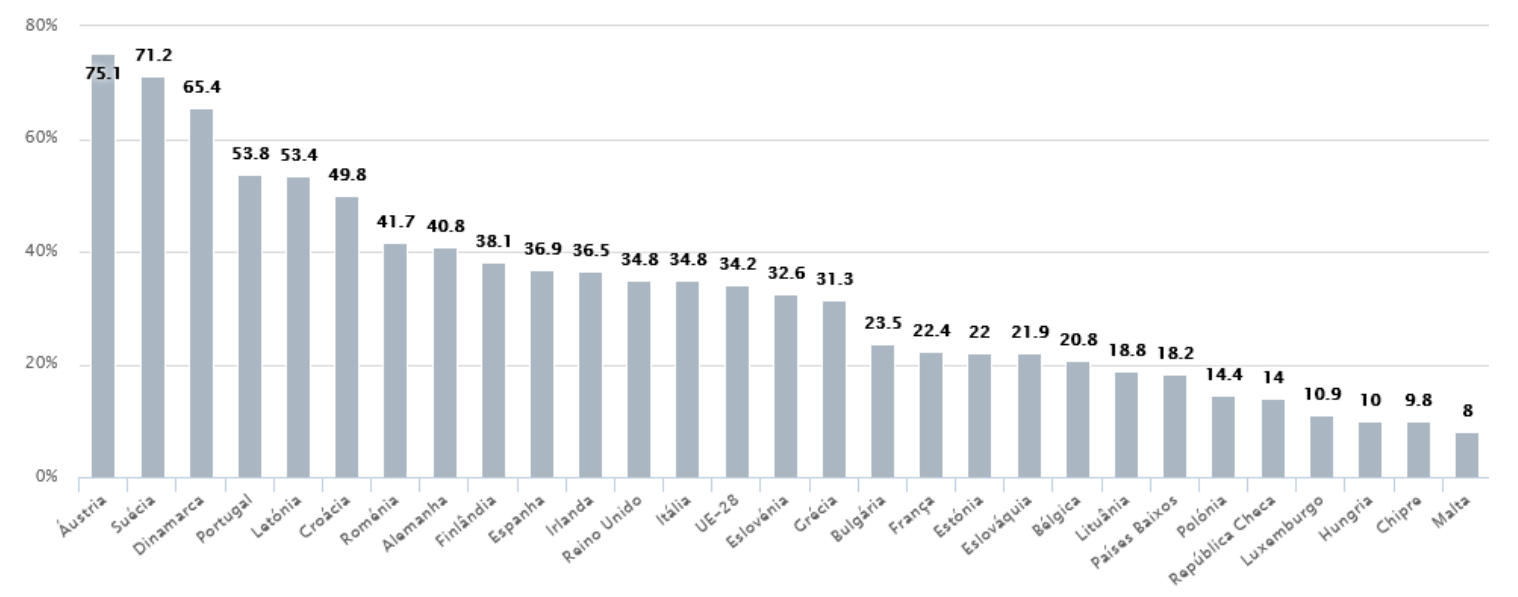

Figure 10. Percentage of incorporation of renewables in the electricity sector, in the EU-28, in 2019

Cogeneration systems can be divided into three types of technologies: reciprocating engines

Diesel cycle - mainly fueled by fuel oil or diesel;

Otto cycle - fueled with gaseous fuels (natural gas or propane);

Gas Turbines - Usually consuming Natural Gas; 
Steam Turbines - Generate electricity by expanding steam produced in a boiler.

Cogeneration plants are classified according to the type of cycle in which they operate: Simple Cycle - When a type of generating equipment is installed;

Combined Cycle - When a cycle with alternative engine(s) or gas turbine(s) is combined with a steam turbine where the steam generated by the thermal exploitation of the exhaust gases of the turbine(s) is used gas or engine(s).

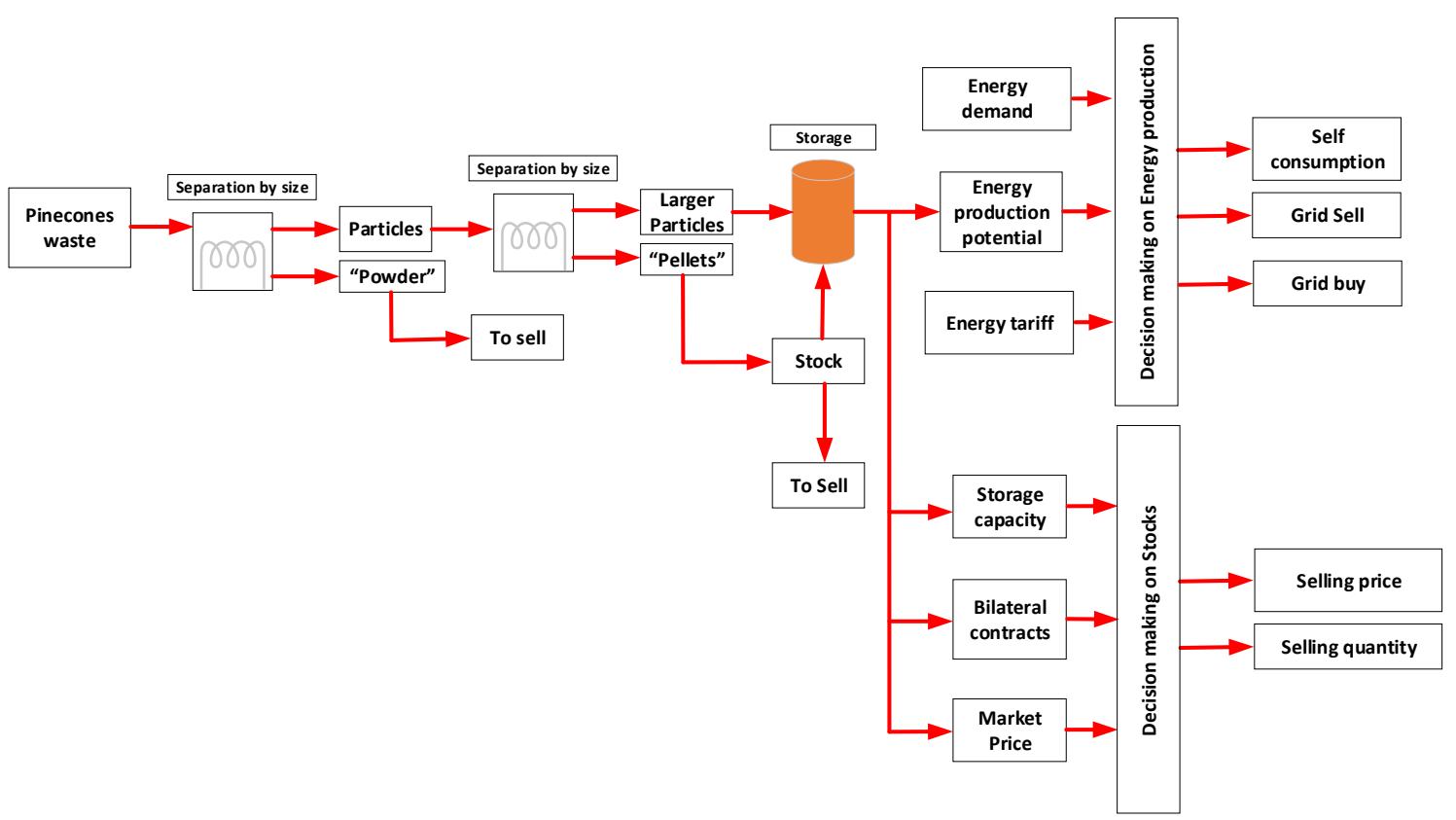

Combustion simultaneously covers the chemical reactions that occur.

they produce in the course of complete or partial oxidation of carbon and hydrogen.

Fuel + fuel $->$ reaction products + heat

The combustion of biomass takes place in 4 stages:

Drying: the water contained in the wood is evaporated;

Pyrolysis $\left(280^{\circ} \mathrm{C}\right)$ : ensured by the entry of primary air, the wood decomposes and releases volatile materials;

Inflammation of gases $\left(500^{\circ} \mathrm{C}\right)$ : occurs with the entry of secondary air, volatile matters burn in the gaseous phase, causing a diffused flame;

Combustion: the carbon residue (ember) oxidizes by surface reaction.

\section{Conclusions}

Using Biomass Energy has several advantages, such as the fact that it's a renewable energy, it does not pollute, emitting no carbon dioxide (according to the natural carbon neutral cycle), it is highly reliable and the response to demand variations is high, solid biomass is extremely cheap, its ash being less harmful to the environment and there is less corrosion of equipment (boilers, ovens, etc.). 
Around $80 \%$ of the energy the EU consumes comes from fossil fuels - oil, natural gas and coal with a significant and growing part of this energy being imported from outside the EU. In imports, it should be noted that currently the dependence on imported oil and gas is $50 \%$, with a tendency to increase, which places the EU in a situation of vulnerability in the face of possible reductions in supply or price increases.

Apart from economic reasons and supply vulnerability, fossil fuels still cause serious environmental damage, since their use is one of the main causes of emissions into the atmosphere of $\mathrm{CO} 2$, the most significant of the Greenhouse Gases (GHG) .

The increase in energy production from renewable sources makes the consumption of fossil fuels decrease. Thus, in addition to respecting the environment, given the autochthonous nature of these energy sources, the risks of dependence on the outside are lower.

There is a contribution to alleviating the greenhouse effect and climate change: When the energy stored in biomass is used, GHG is emitted, in particular carbon dioxide (CO2). However, this amount of $\mathrm{CO} 2$ is less than that consumed when producing biomass through photosynthesis. This is because the root - which accumulates some of the carbon produced by the plant - will tend to remain in the soil. Thus, the use of biomass as a fuel actually gives rise to a small net decrease in $\mathrm{CO} 2$ in the atmosphere. If the biomass is not combusted, its natural decomposition would give rise to the same amount of $\mathrm{CO} 2$. If biomass is used in energy production, it also contributes to reducing the use of fossil fuels, avoiding $\mathrm{CO} 2$ emissions.

Promotion of rural development, job creation and the local/regional economy is another advantage. In rural areas, we must invest in endogenous resources as a way of creating wealth, which fulfils the three main objectives of sustainability: social cohesion, economic development and environmental protection. The use of forest biomass for energy purposes fits precisely in this scope, as it: allows the creation of economic opportunities, social opportunities and the enhancement and protection of the environment.

Decrease in the risk of forest fire is also a advantage. Structural fire risk is, among other things, directly related to the amount and type of fuel available and to weather conditions. This risk is particularly high in the southern regions of Europe, so the north of Portugal and the south of Galicia are no exceptions. By influencing the amount of fuel present by the removal of primary forest biomass, in addition to generating greater economic value for the forest property (if used for energy production), it contributes to mitigating not only the problem of fires, but also of others, whether of sanitary origin (proliferation of pests and diseases) or accessibility to the interior of forest spaces.

\section{REFERENCES}

[1] Rapid renewable statistics, DGEG - Directorate General for Energy and Geology, Directorate of Energy and Statistical Planning Services, available online: https://www.dgeg.gov.pt/media/frujgmcv/renovaveis-202109.pdf, last access $18^{\text {th }}$ of September of 2021

[2] Policy Brief: Biomass for Heat, Bioenergy Europe Statistical Report 2020, September of 2020

[3] Directorate-General for Energy and Geology - energy in numbers, available online: https://www.dgeg.gov.pt/pt/estatistica/energia/publicacoes/energia-em-numeros/ , last access $18^{\text {th }}$ of September of 2021

[4] Eurostat - renewable energy statistics, available online: https://ec.europa.eu/eurostat/statisticsexplained/index.php/Renewable_energy_statistics , last access $18^{\text {th }}$ of September of 2021

[5] Directorate-General for Energy and Geology - energy statistics, available online: https://www.dgeg.gov.pt/pt/estatistica/energia/ , last access $18^{\text {th }}$ of September of 2021 
Advanced Energy: An International Journal (AEIJ), Vol. 9, No. 1, January 2022

[6] Directorate-General for Energy and Geology - energy balances, available online: https://www.dgeg.gov.pt/pt/estatistica/energia/balancos-energeticos/ , last access $18^{\text {th }}$ of September of 2021

\section{AUTHOR}

Nuno A. S. Domingues, Pós Doc in Science Communication from FCSH-UNL (2021), Pós Doc in Electrical Engineering and Computer Science from IST (2020), $\mathrm{PhD}$ in Electrical Engineering and Computer Science from FCT-UNL (2015), Master in Electrical Engineering and Computer Science from IST (2008), Undergraduate (5year) degree in Electrical Engineering from ISEL (2005).

His topics of research include sustainability, efficiency, clean technologies, mobility

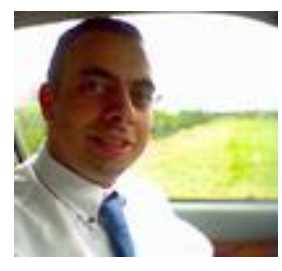
and transport, sustainable consumption, electricity markets modelling and simulation, energy systems, SCADA and DSS, decision making, regulation, intelligent optimization, evolutionary algorithms, machine learning, e-learning, science communication and education.

He is a Professor in ISEL. He holds a Problem Based Learning and Excelence on Teaching and Learning diploma by UNESCO and the internationally Information Technology ECDL qualification.

https://publons.com/researcher/1176435/nuno-domingues/metrics/ https://www.isel.pt/docentes/nuno-alexandre-soares-domingues https://scholar.google.pt/citations?user=-mtxKk8AAAAJ\&hl=pt-PT https://www.linkedin.com/in/nuno-domingues-a1401916/ https://orcid.org/0000-0003-0763-8106 